This article has been scanned by iThenticat No plagiarism detected

Volume 3, Issue 2, April 2021

p. 87-97

\title{
THE DEGREE OF EFFECTIVENESS ORGANIZATIONAL CONFLICT MANAGEMENT BY SECONDARY SCHOOL PRINCIPALS IN THE NORTHERN REGION WITHIN THE GREEN-LINE
}

http://dx.doi.org/10.47832/2757-5403.2-3.8

Jamal S. ZAID1

\begin{abstract}
:
The study aimed to reveal the degree of effectiveness of the organizational conflict management among secondary school principals in the Triangle area within the Green Line from the point of view of the teachers.

The study adopted the using the descriptive survey method, the school community is made up of all secondary school teachers (2177) in the Triangle area within the green line. the sample of the study was (372) teachers, who were chosen by the simple random sampling. The study results showed that the degree of organizational conflict management among secondary school principals was high. The results showed also that the most used conflict strategy was cooperation strategy, followed by settlement, withdrawal, competition and avoidance strategies. There are significant differences at the organizational conflict management degree among secondary school principals du the variables of "academic qualification" at the compromise strategy and cooperation strategy in "Bachelor" only.

Depending on the study results, the researcher recommends that the need to work to increase the knowledge and awareness of secondary school principals of conflict management strategies in general, and to urge them to use cooperation and settlement strategies in particular, and to avoid competition and avoidance strategies, through holding meetings and training courses. Paying attention to conflict situations and researching their causes, following the positive strategy best suited to the situation and making use of it in strengthening relationships, belonging and improving performance.
\end{abstract}

Key words: Organizational Conflict Management Strategies, Secondary Schools, Green Line.

\footnotetext{
${ }^{1}$ Researcher, Elahlya High School, Palestine, jamal zaid@hotmail.com, https://orcid.org/0000-0003-0735$\underline{7646}$
}

Copyright (C) Published by IJHER Journal, www.ijherjournal.com

Rimar Academy, Fatih, Istanbul, 34093 Turkey

All rights reserved 


\title{
THE DEGREE OF EFFECTIVENESS ORGANIZATIONAL CONFLICT \\ MANAGEMENT BY SECONDARY SCHOOL PRINCIPALS IN THE NORTHERN \\ REGION WITHIN THE GREEN-LINE
}

\section{درجة فاعلية إدارة الصراع التنظيمي لاى مديري المدارس الثانوية في منطقة المثلث

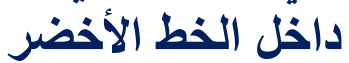

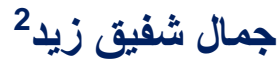

\begin{abstract}
الملخص

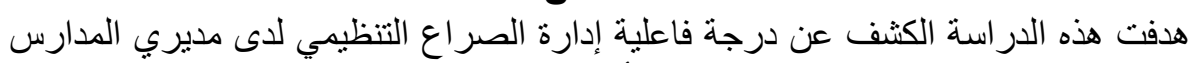

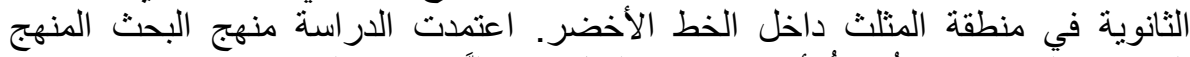

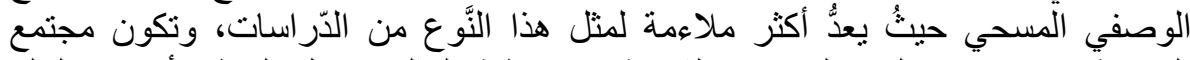

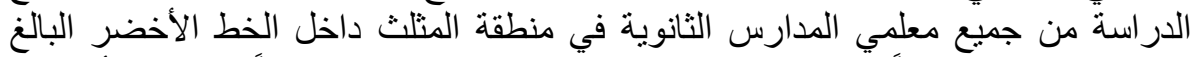

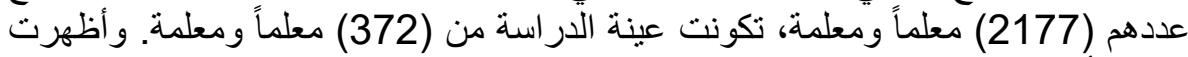

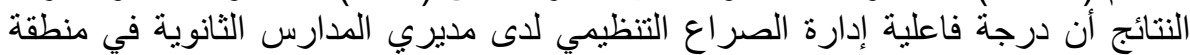

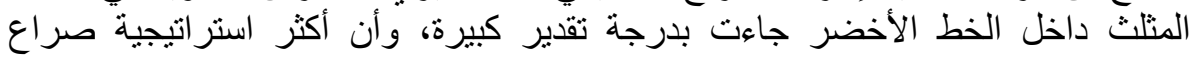

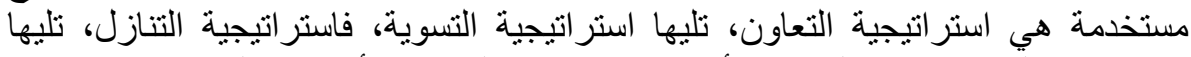

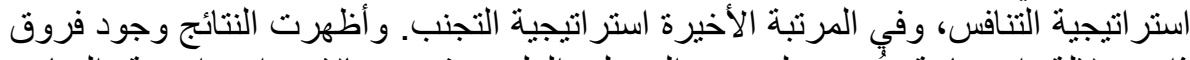

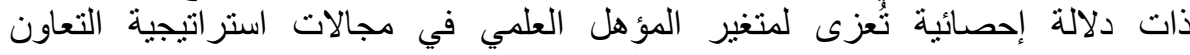

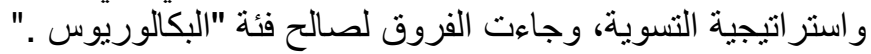

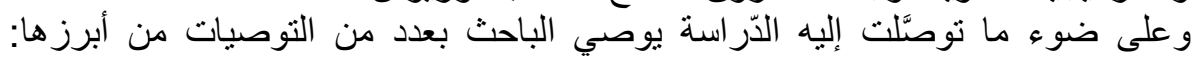

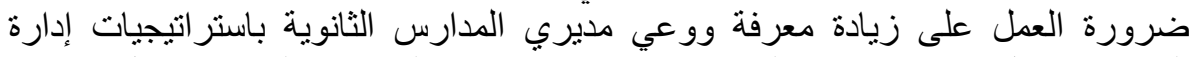

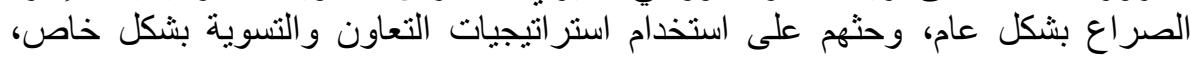

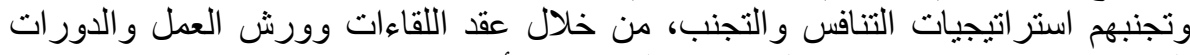

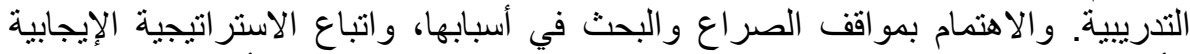

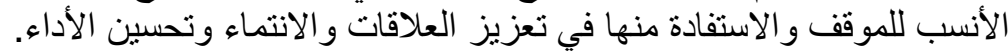
الكلمات المفتاحية: استراتيجيات إدارة الصريز العراع التنظيمي، المدارس الثناء الثانوية، الخط

الأخضر.
\end{abstract}

المقدَّمة:

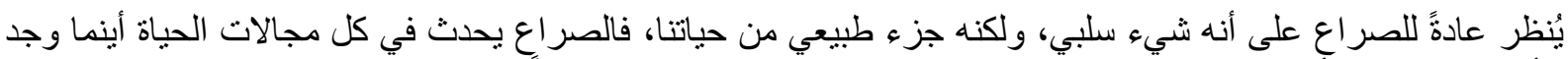

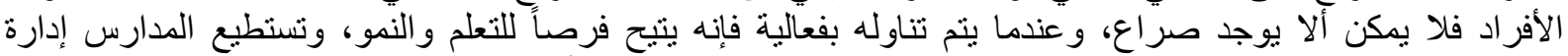

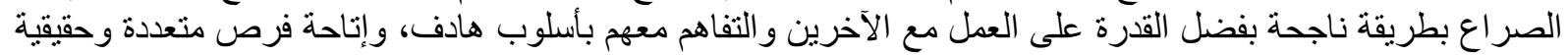
لإشر الك المعلمين في إدارة المدرسة.

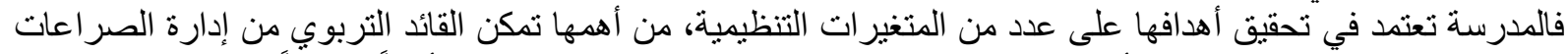

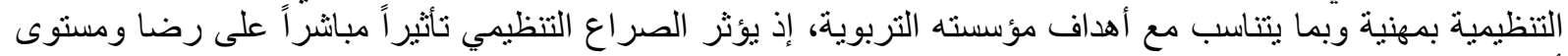

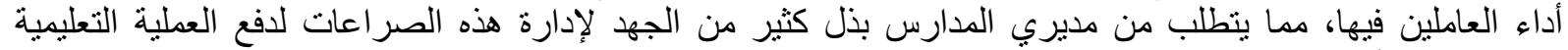

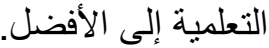

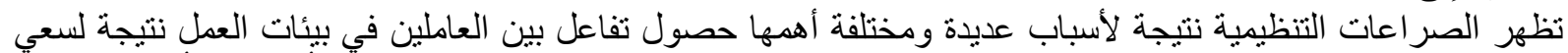

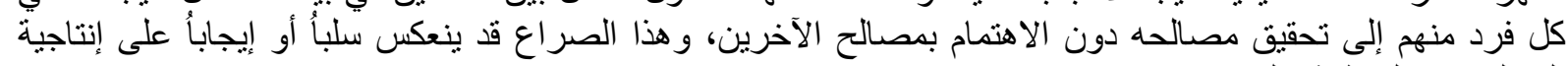

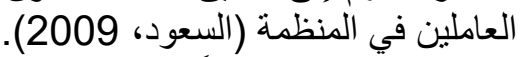

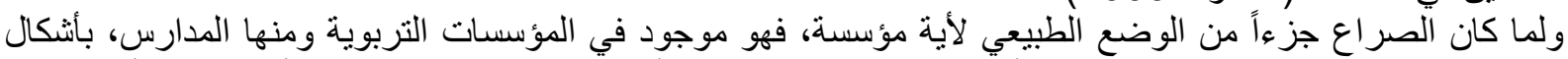

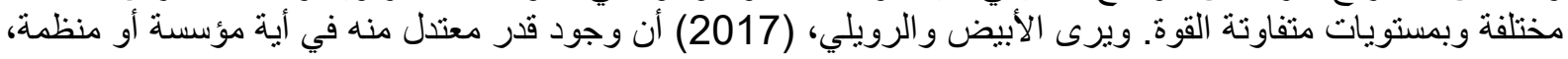

jamal zaid@hotmail.com،الباحث، المدرسة الأهلية، فلسطين 
يحقق لها أعلى مستوى من الفعالية، إذا تمت إدارته بطريقة جيدة. ومن هنا تظهر عملية إدارة الصراع إع التي أصبحت

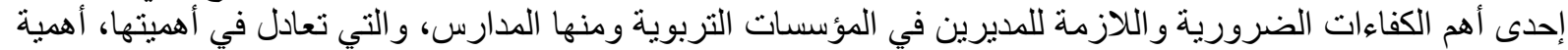
عملية التخطيط أو عملية اتخاذ القرار الترات.

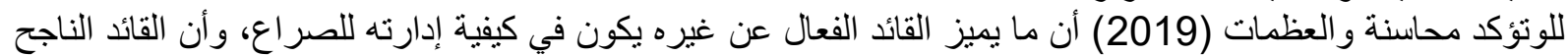

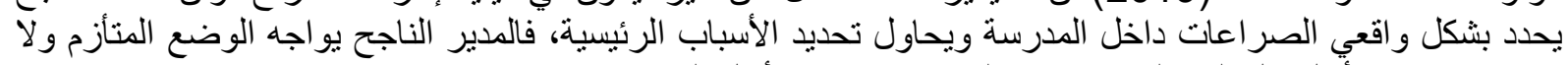

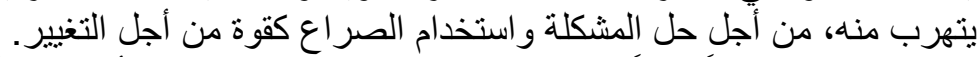

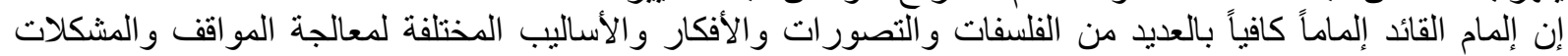

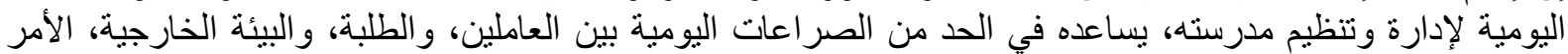

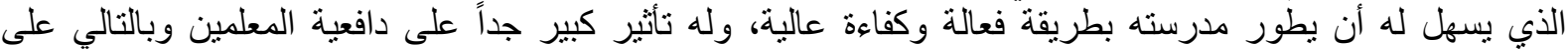
مستوى أدائهم.

المحور الأول: الإطار العام للاراسة

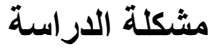

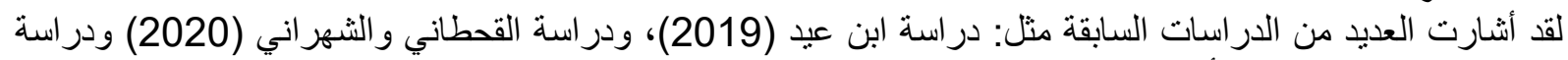

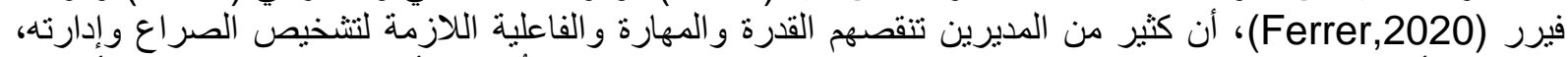

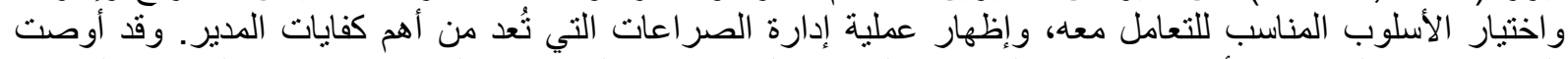

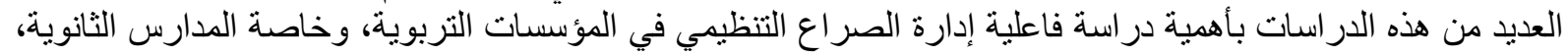

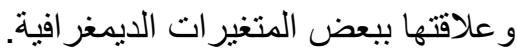

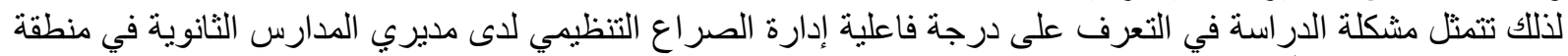

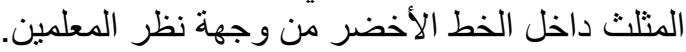

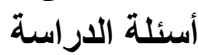

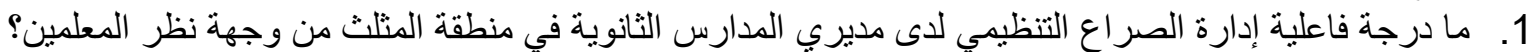

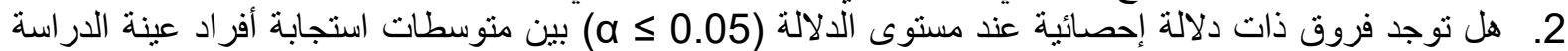

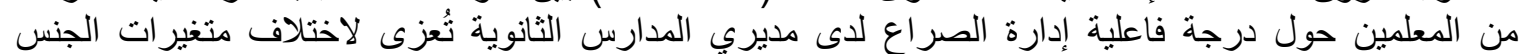

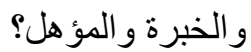

$$
\text { أهداف الاراسة }
$$

1. بيان درجة فاعلية مديري المدارس الثانوية في منطقة المثلث داخل الخط الأخضر لإدارة الصراع التنظيمي في

مدارسهم. 2. الكثف عن الفروق في استجابات أفر اد عينة الدراسة حول درجة فاعلية مديري المدارس الثانوية في منطقة المثلث

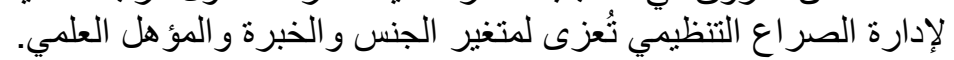

أهمية الدراسة أكية

تكمن أهمية هذه الدر اسة في ناحيتين، ناحية علمية (نظرية) وناحية عملية (تطبيقية).

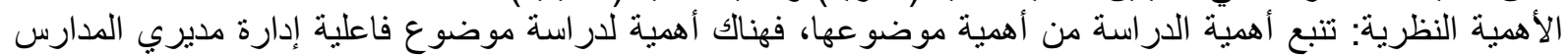

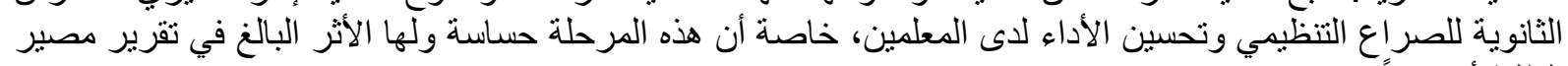

الطلبة أكاديمياً.

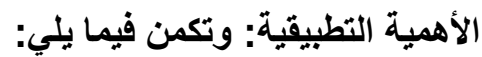
1. الوقوف على بعض المنفة ونكنير آت الإدارية والديمغر افية المرتبطة و المنبئة بدرجة فاعلية مديري المدارس الثانوية في

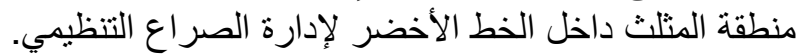
2. التوصية إلى صناع القرار الاهتمام بوضع الاستر اتيجيات العملية لإدارة الصر اعات التنظيمية وإعداد البرامج لرفع مستوى أداء معلميهح.

الطريقة والإجراءات

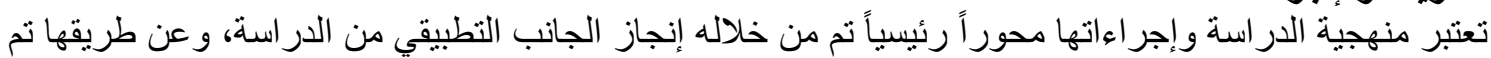

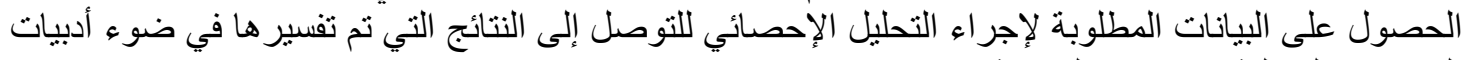

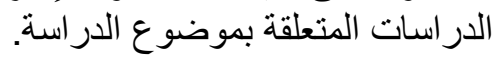




\section{THE DEGREE OF EFFECTIVENESS ORGANIZATIONAL CONFLICT \\ MANAGEMENT BY SECONDARY SCHOOL PRINCIPALS IN THE NORTHERN \\ REGION WITHIN THE GREEN-LINE}

منهج الاراسة

اعتمدت الدراسة المنهج الوصفي المسحي للإجابة عن تساؤلات الدراسة، وذلك لمناسبته وطبيعة هذه الدراسة و أهدافها.

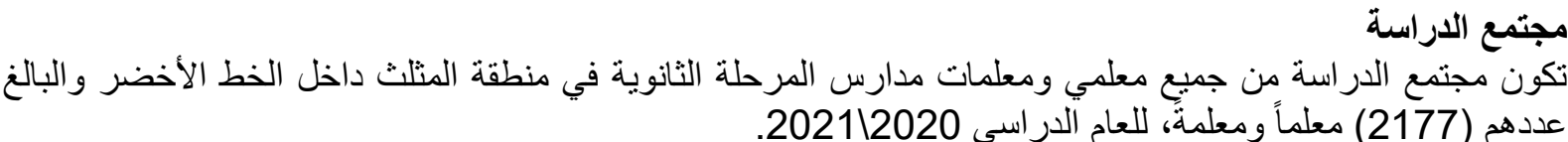

عينة الاراسة

تم اختيار عينة عشوائية (العشو ائية البسيطة) بلغ عددها (372) معلماً ومعلمةً.

أدوات الدراسة

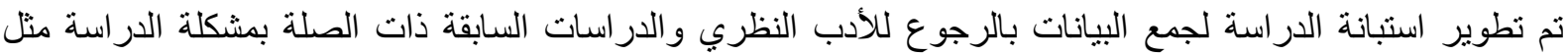

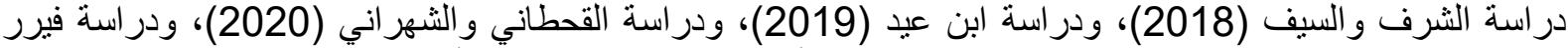

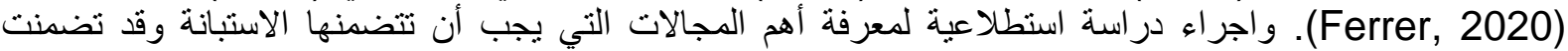

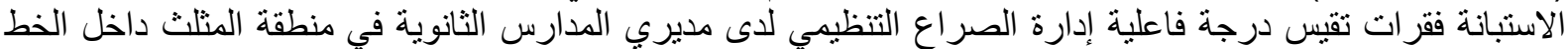

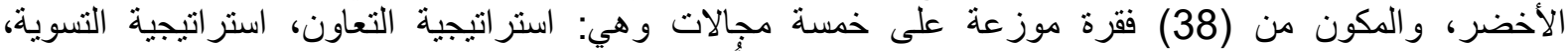
استر اتيجية التنازل، استر اتيجية التنافس، واستر اتيجية التجنب. و وأَستخدم في الاستبانة مقياس ليكرت التئ الخماسي.

المحور الثاني: الإطار النظري

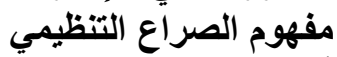

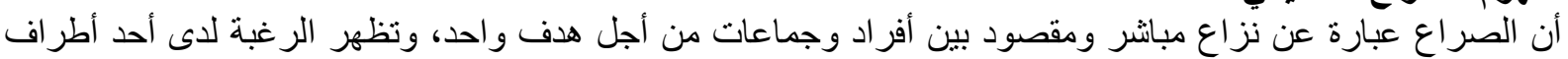

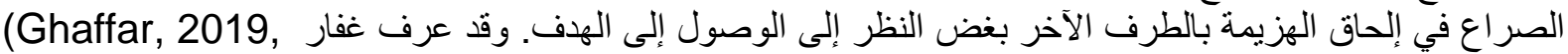

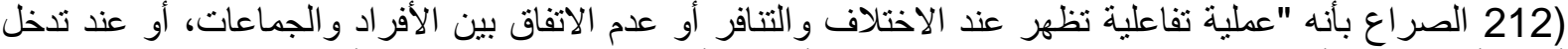

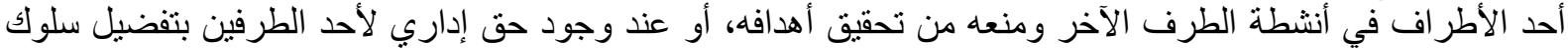

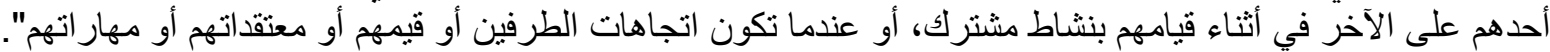

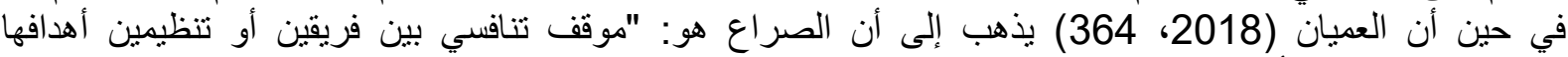

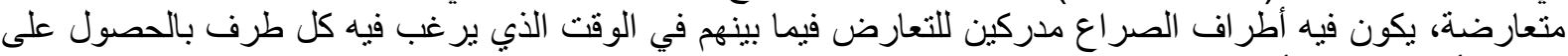

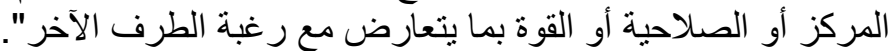

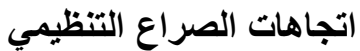

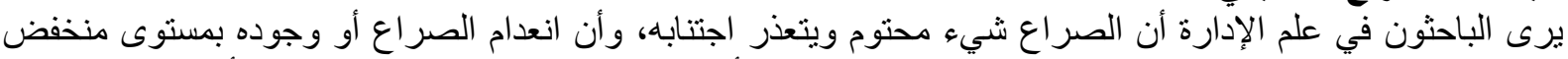

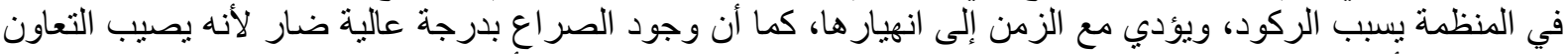

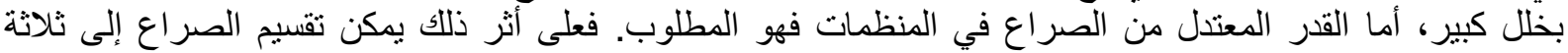

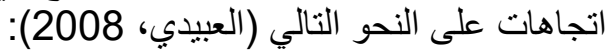

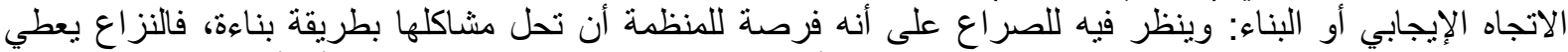

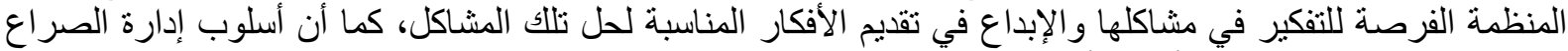

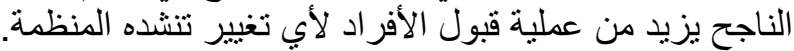

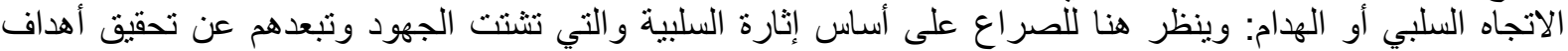

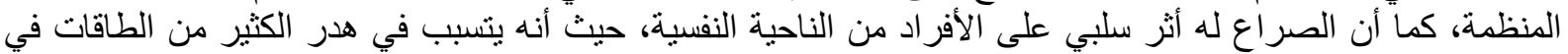
مو اضيع ومشاكل جانبية.

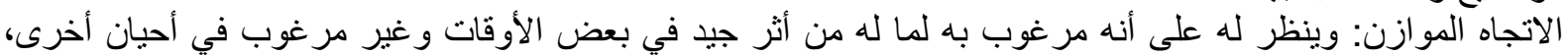

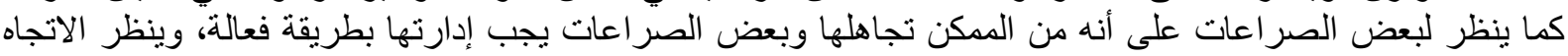

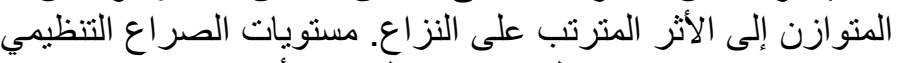

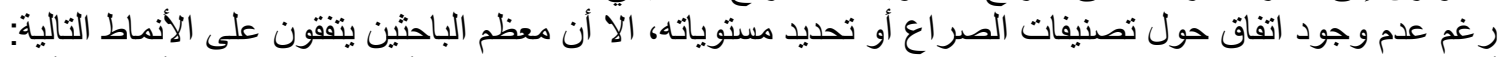

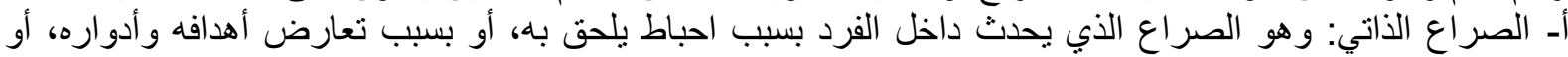

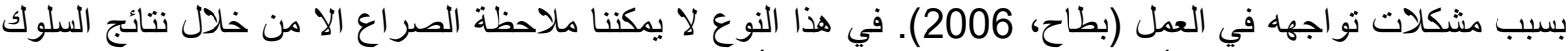
و القرار ات التي يتخذها العامل أو الموظف ما إن إن كانت صائبة أم لا. 


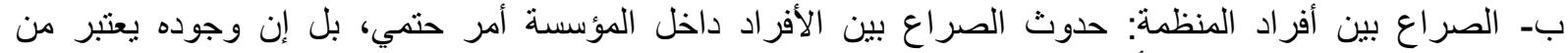

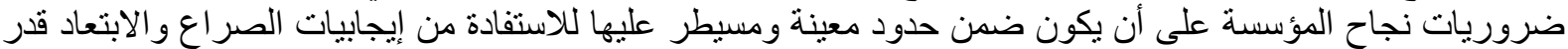
الإمكان عن سلبياتها التي من شأنها أن تحد من إنتاجية إنية الأفر اد و المؤسية.

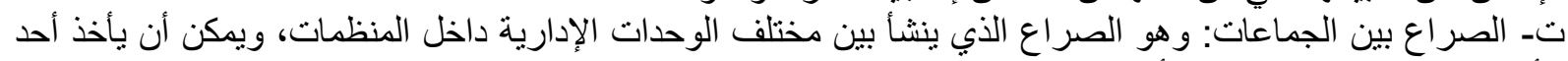

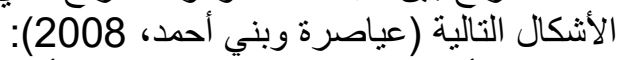
الصراع الأفقي: ويحدث عادة بين العين العاملين أو الدوائر الإدارية من المستوى التنظيمي نفسه، أو الصر العاع العمودي: ويحدث

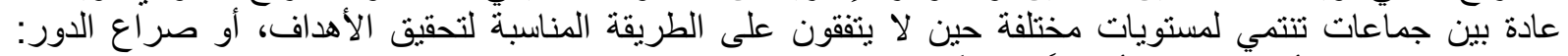

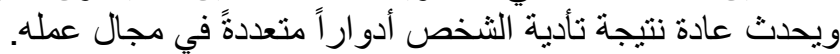

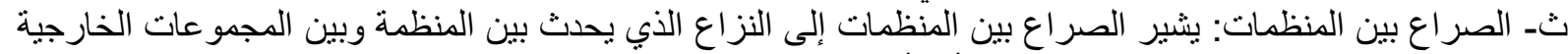

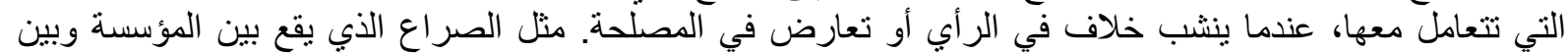

غير ها من المؤسسات التي تز احمها في نفس النشاط و على نفس العماء التهاء (Radford, 2013).

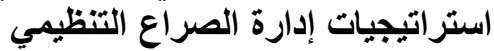

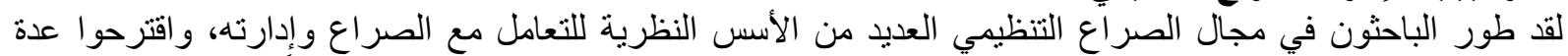

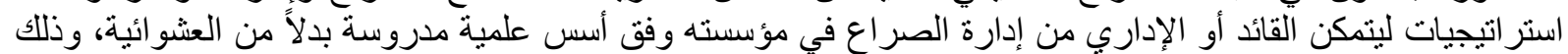

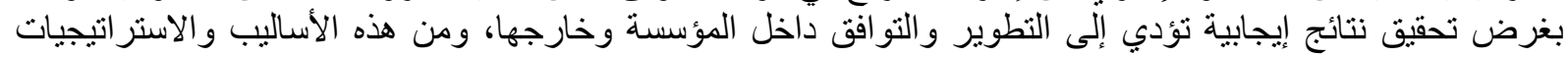

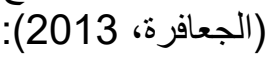

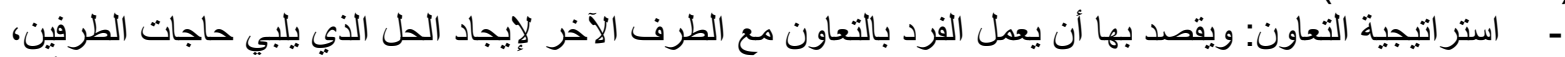

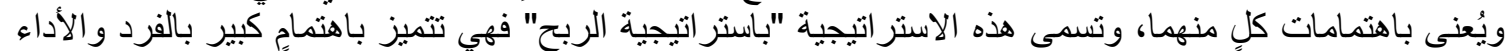

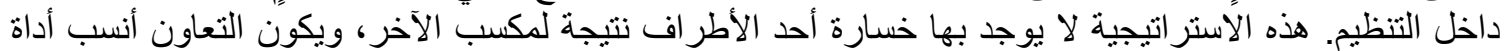

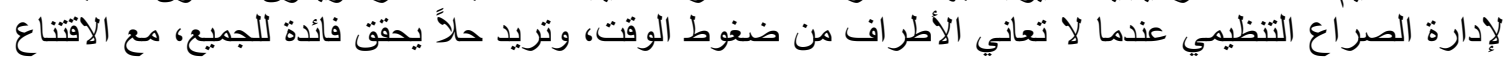
بأهمية المصالح المشراع: المشتركة.

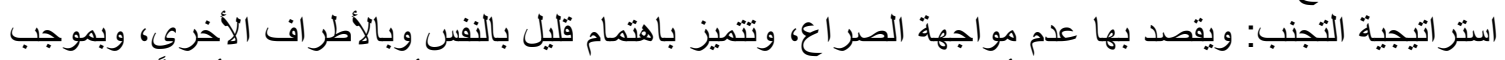

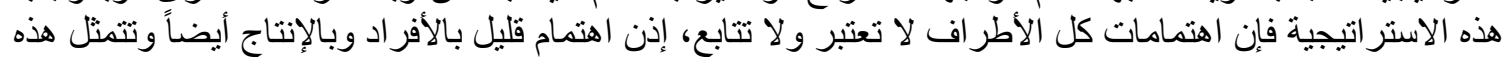

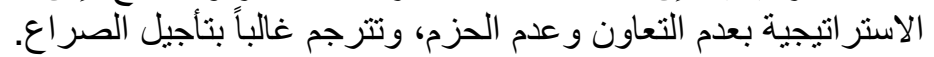

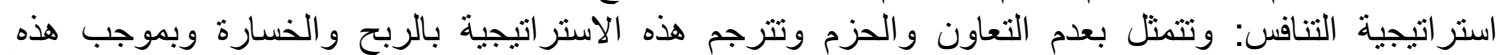

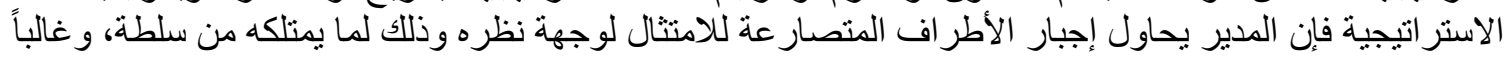

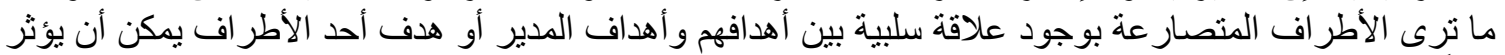

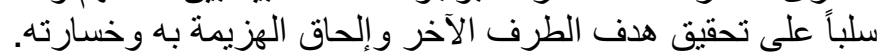

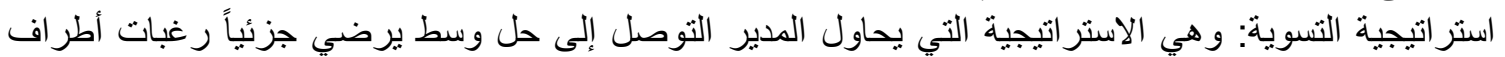

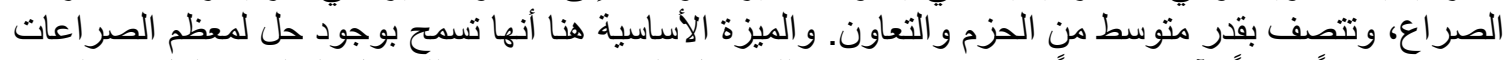

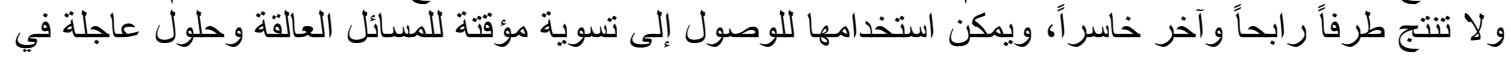

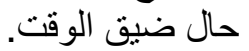

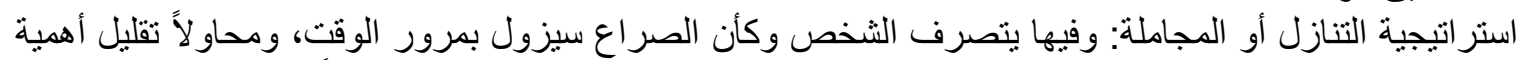

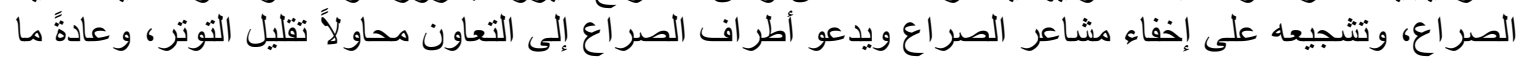

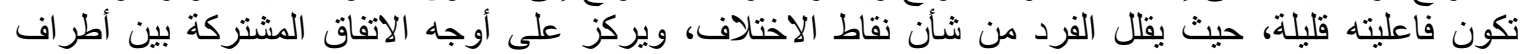

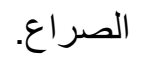

المحور الثالث: نتائج الاراسة ومناقثتها

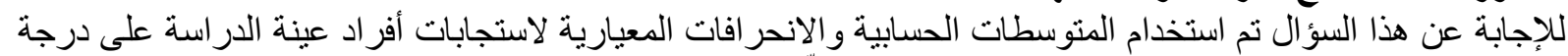

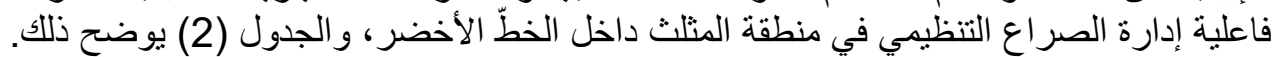

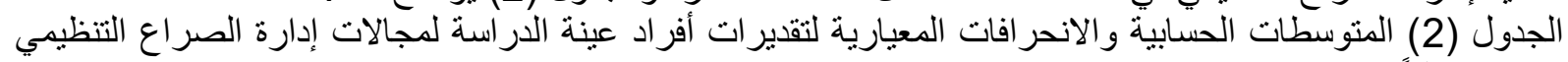

\begin{tabular}{|c|c|c|c|c|c|}
\hline الدرجة & الرتبة & المعياري الانح & المتوسط الحسابيّ & المجالات & 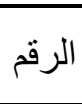 \\
\hline كبيرة & 1 & 0.93 & 3.71 & استر اتيجية التعاون & 1 \\
\hline كبيرة & 2 & 0.78 & 3.56 & استر اتيجية التسوية & 2 \\
\hline كبيرة & 3 & 0.79 & 3.48 & استر اتيجية التنازل & 3 \\
\hline كبيرة & 4 & 0.68 & 3.40 & استر اتيجية التنافس & 4 \\
\hline
\end{tabular}




\section{THE DEGREE OF EFFECTIVENESS ORGANIZATIONAL CONFLICT}

MANAGEMENT BY SECONDARY SCHOOL PRINCIPALS IN THE NORTHERN

REGION WITHIN THE GREEN-LINE

\begin{tabular}{|c|l|l|l|r|r|}
\hline الدرتر اتيجية التجنب الكلية & 5 \\
\hline
\end{tabular}

يُيِيّن الجدول (2) أنَّ درجة فاعلية إدارة الصراع التنظيمي جاءت (كبيرة)، وكان أولها مجال استراتيجية التعاون (3.71)، وفي المرنبة الأخيرة مجال استر اتيجة فئة التئة التجنب (2.92).

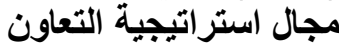

الجدول (3) المتوسطات الحسابية والانحرافات الماتوات المعيارية لتقديرات أفراد عينة الدراسة لمجال استراتيجية التعاون من

مجالات إدارة الصر اع التنظيمي مرتبة تنازلياً

\begin{tabular}{|c|c|c|c|c|c|}
\hline 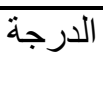 & 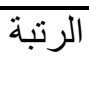 & 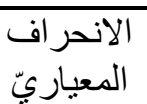 & 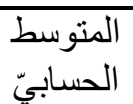 & 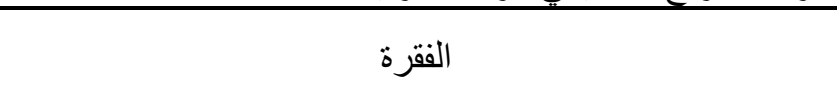 & الرقم \\
\hline كبيرة & 1 & 1.04 & 3.81 & يساعد المدير المعلمين على حل المشكلات التي تواجهرم & 32 \\
\hline 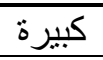 & 2 & 1.00 & 3.77 & يضع المدير أهدافاً مشتركة يتطلب إنجاز ها تعاون الجميع & 31 \\
\hline كبيرة & 3 & 1.01 & 3.74 & الجعيع المدير مع معلميه للوصول إلى قرارات مقبولة على & 35 \\
\hline كبيرة & 4 & 1.02 & 3.74 & يتفهم المدير وجهات نظر الطرف الآخر & 33 \\
\hline كبيرة & 5 & 1.04 & 3.72 & يشجع المدير المعلمين على فهم مشكلات العمل قبل البدء بحلها & 36 \\
\hline كبيرة & 6 & 1.03 & 3.69 & يسعى المدير لتوجيه أفكار المعلمين ومناقشتها & 34 \\
\hline كبيرة & 7 & 1.08 & 3.69 & 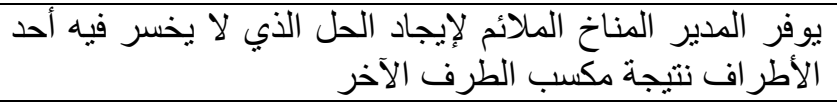 & 37 \\
\hline كبيرة & 8 & 1.09 & 3.58 & يشرك المدير المعلمين في وضع الخطط و البرامج لمواجهة & 38 \\
\hline كبيرة & & 0.93 & 3.71 & الكلية & الدرج \\
\hline
\end{tabular}

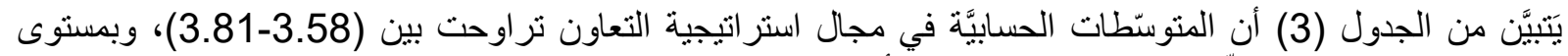

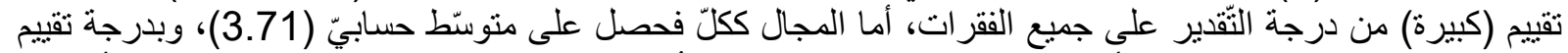

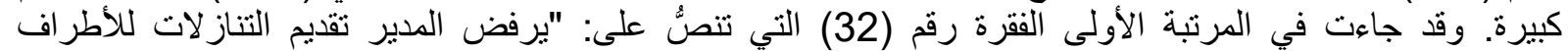

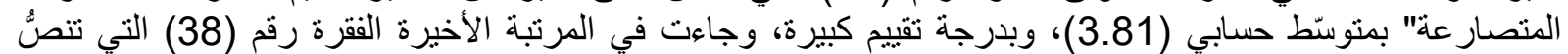

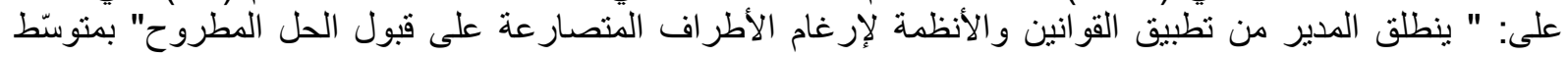
حسابي (3.58) وبدرجة تقنييم كبيرة. مجال استراتيجية التسوية تم حساب المتوسطات الحسابية والانحر افات المعيارية لاستجابات أفر اد عينة الدراسة لفقرات مجال استر اتيجية التسوية

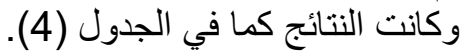
الجدول (4) المتوسطات الحسابية والانحر افات المعيارية لتقديرات أفراد عينة الدراسة لمجال استراتيجية التسوية من

\begin{tabular}{|c|c|c|c|c|c|}
\hline 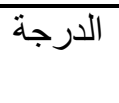 & 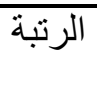 & 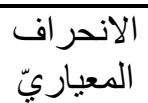 & 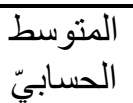 & 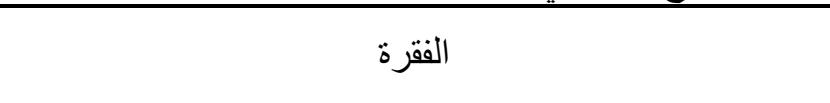 & 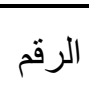 \\
\hline كبيرة & 1 & 0.97 & 3.78 & الر أبي الأنسبر إلى وجهة نظر أطر اف الصراع حتى بتفقا على & 22 \\
\hline كبيرة & 2 & 0.97 & 3.70 & يقرب المدير وجهات النظر المتباينة بين أطر اف للصر اع & 20 \\
\hline كبيرة & 3 & 1.00 & 3.65 & المتصرح المدير أرضية مشتركة لحسم الخلافات بين الأطر اف & 19 \\
\hline كبيرة & 4 & 1.05 & 3.64 & أطبر اف الصدر اعهداً للوصول إلى حلول متكاملة ترضي جميع & 18 \\
\hline كبيرة & 5 & 1.04 & 3.51 & يعمل المدير على توضيح المكسب والخسارة بين الأطراف & 16 \\
\hline
\end{tabular}




\begin{tabular}{|c|c|c|c|c|c|}
\hline & & & & المتصـار عة & \\
\hline كبيرة & 6 & 1.00 & 3.42 & الصنمد المدير التفاوض القائم على التنازلات بين أطراف & 21 \\
\hline متوسط & 7 & 1.03 & 3.22 & ورضخاضى الأطر افدير المتصنار بعض الأمور للحصول على موافقة & 17 \\
\hline كبيرة & & 0.78 & 3.56 & \multicolumn{2}{|c|}{ لارجة الكلية } \\
\hline
\end{tabular}

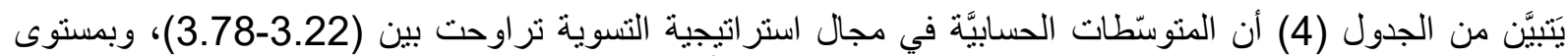

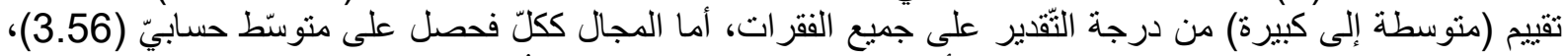

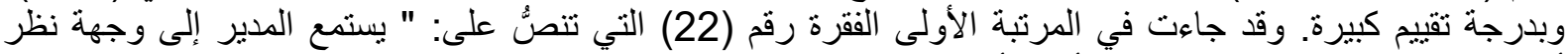

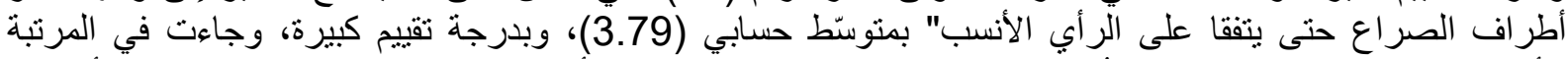

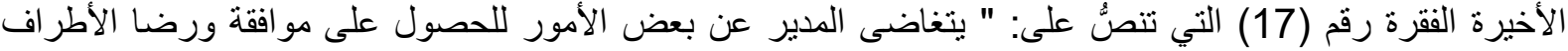

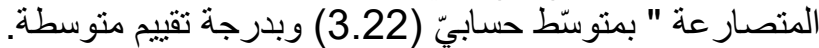
مجال استراتيجية التنازل تم حساب المتوسطات الحسابية والانحر افات المعيارية لاستجابات أفراد عينة الدراسة لفقرات مجال استر اتيجية التسوية

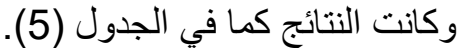

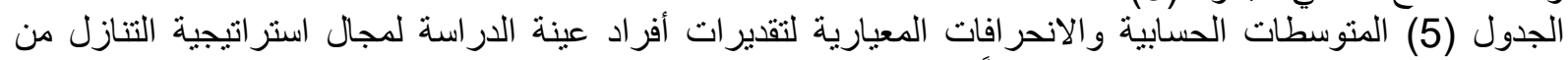
مجالات إدارة الصر اع التنظيمي مرتبة تنازلياً

\begin{tabular}{|c|c|c|c|c|c|}
\hline 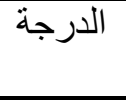 & 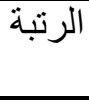 & 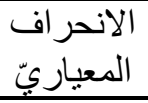 & 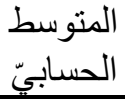 & الفقرة & 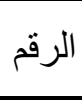 \\
\hline كبيرة & 1 & 1.04 & 3.79 & المتصاول المدير الحفاظ على العلاقات بين الأطراف & 10 \\
\hline كبيرة & 2 & 1.00 & 3.63 & بين الأطراف المتصدير نقاط الاتفاق بدلاً من نقاط الاختلاف & 14 \\
\hline كبيرة & 3 & 1.15 & 3.59 & ير اعي المدير مشاعر أطر اف الصراع & 9 \\
\hline كبيرة & 4 & 1.02 & 3.50 & 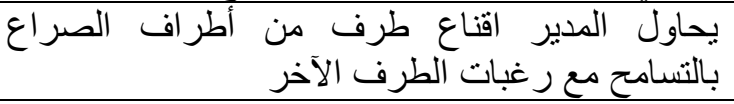 & 15 \\
\hline منوسطة & 5 & 1.06 & 3.22 & للصر اع المدير رغبات الآخرين في الاعتبار عند حله & 13 \\
\hline 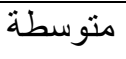 & 6 & 0.99 & 3.18 & يعمل المدير جاهداً على تلبية توقعات أطر اف الصر اع & 12 \\
\hline كبيرة & & 0.79 & 3.48 & & 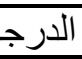 \\
\hline
\end{tabular}

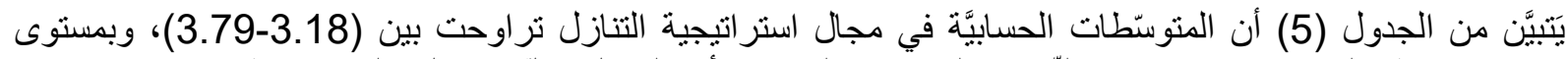

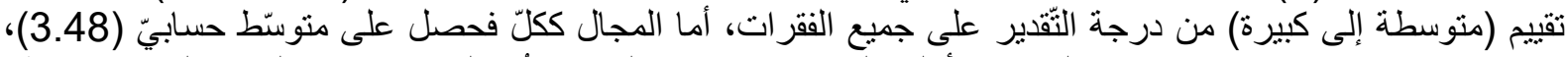

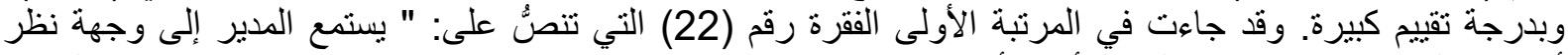

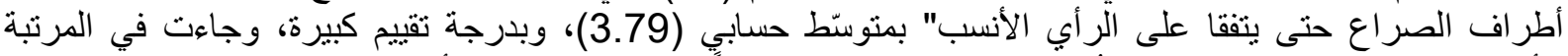

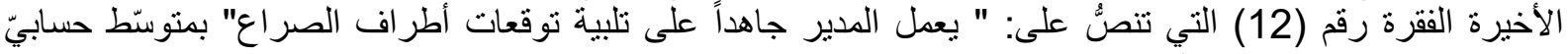

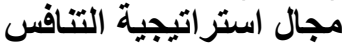
تم حساب المتوسطات الحسابية والانحر افات المعيارية لاستجابات أفراد عينة الدراسة لفقرات مجال استر اتيجية التسوية

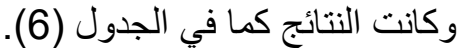

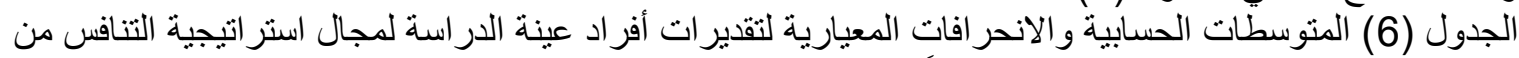
مجالات إدارة الصر اعنواع التنظيمي مرنبة تنازلياً

\begin{tabular}{|c|c|c|c|c|c|}
\hline الدرجة & الرتبة & المعياريّ الانحر & 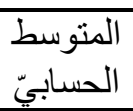 & الفقرة & الرقم \\
\hline كبيرة & 1 & 0.92 & 3.70 & الصرالب المدير بتحديد واجبات ومسؤوليات كل من طرفي & 26 \\
\hline
\end{tabular}




\begin{tabular}{|c|c|c|c|c|c|}
\hline 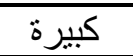 & 2 & 1.09 & 3.62 & يعتمد المدير سياسة تشجيع المنافسة بديلاً للصر اعات & 23 \\
\hline كبيرة & 3 & 1.07 & 3.53 & بينهم اجه المدير الأطر اف المتصار عة مباشرة إذا حدث صراع & 27 \\
\hline كبيرة & 4 & 1.05 & 3.40 & يناسبراً لمصديرة أطراف الصدر اع على قبول الحل الذي يعتبر & 29 \\
\hline متوسطة & 5 & 1.01 & 3.37 & المنطلق المدير من تطبيق القو انين و الأنظمة لإرغام الأطر اف & 30 \\
\hline متوسطة & 6 & 1.04 & 3.13 & يرفض المدير تقديم التناز لات للأطر اف المتصار عة & 25 \\
\hline 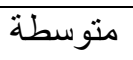 & 7 & 1.19 & 3.04 & يستخدم المدير سلطته الإدارية لحل الصر اع بالقوة & 24 \\
\hline كبيرة & & 0.68 & 3.40 & كلية & 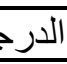 \\
\hline
\end{tabular}

يَتبيَّن من الجدول (6) أن المتوسيّات الحسابيَّة في مجال استراتيجية التنافس تراوحت بين (3.04-3.70)، وبمستوى

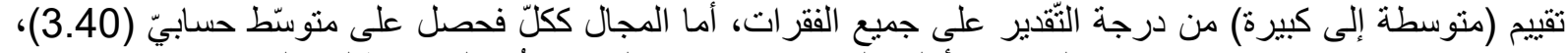

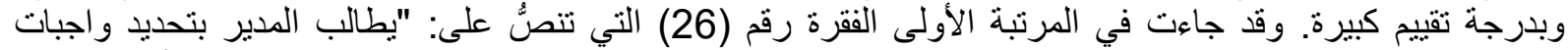

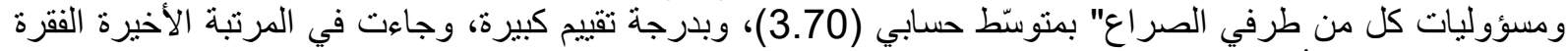

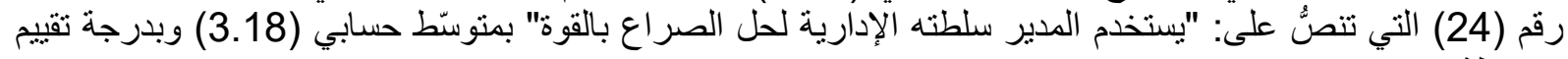
منوسطة. مجال استراتيجية التجنب التبون تم حساب المتوسطات الحسابية والانحر افات المعيارية لاستجابات أفر اد عينة الدراسة لفقرات مجال استراتيجية التجنب

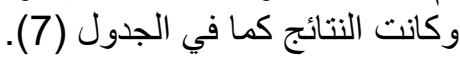
الجدول (7) المتوسطات الحسابية والانية الانحر افات المعيارية لتقديرات أفراد عينة الدراسة لمجال استراتيجية التجنب من

\begin{tabular}{|c|c|c|c|c|c|}
\hline 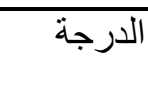 & 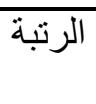 & 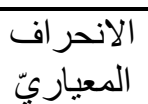 & 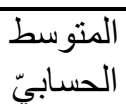 & 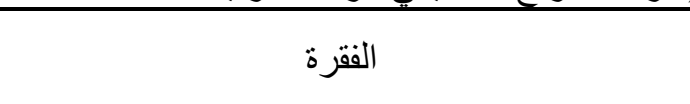 & 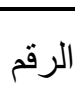 \\
\hline منوسطة & 1 & 1.22 & 3.19 & خيلافنب مع المعلمين اتخاذ مو اقف من شأنها أن تؤدي إلى & 7 \\
\hline متوسطة & 2 & 1.21 & 3.11 & يتحاثىى المدير الموضو عات المسببة للصر اع & 5 \\
\hline متوسطة & 3 & 1.17 & 2.96 & الاطظفرى المتير النقاش حول نقاط الخلاف مع & 2 \\
\hline متوسطة & 4 & 1.23 & 2.85 & يخفف المدير من حدة الصر اع بإهمالها & 3 \\
\hline متوسطة & 5 & 1.23 & 2.73 & أطنجاف الصراع المدير مشاعر الغضب و الإحباط للى & 8 \\
\hline متوسطة & 6 & 1.22 & 2.69 & المدرسة المدير الصر اعات بين المعلمين في & 4 \\
\hline متوسطة & & 0.88 & 2.92 & & الدر \\
\hline
\end{tabular}

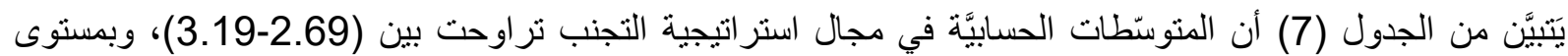

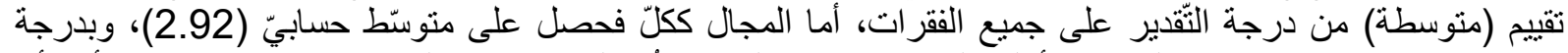

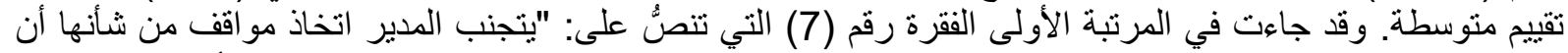

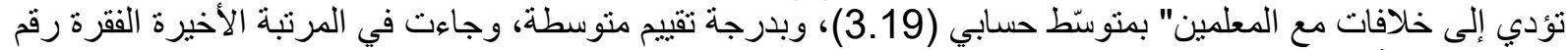

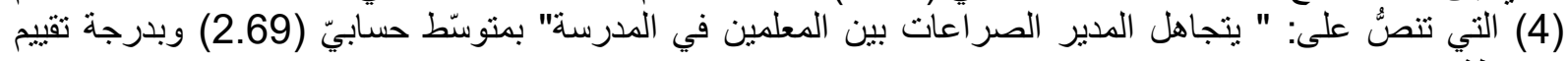

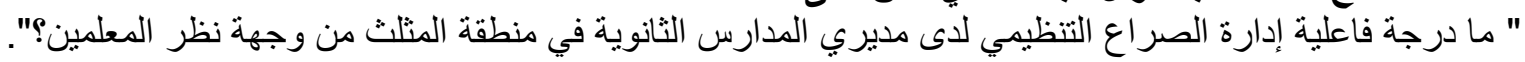




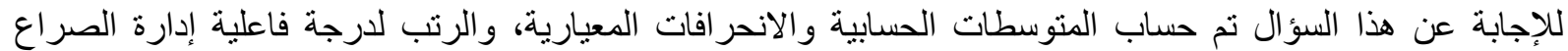

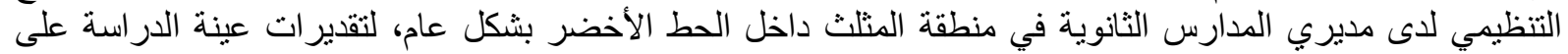

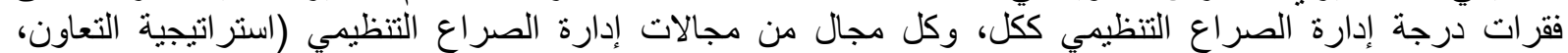

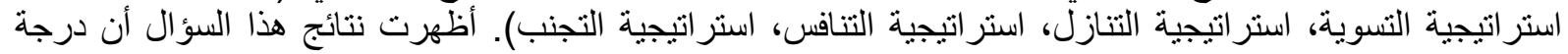

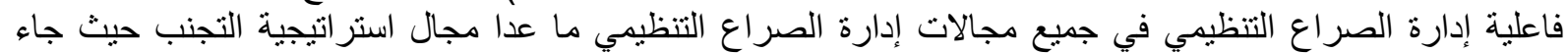

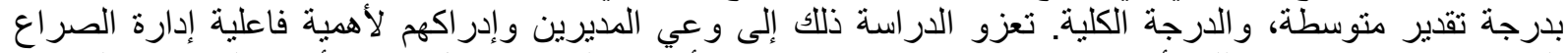

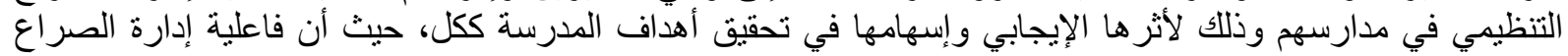

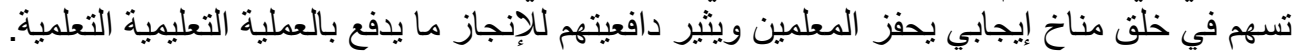

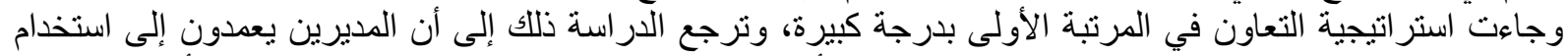

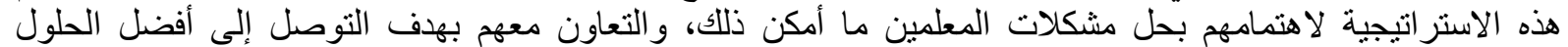

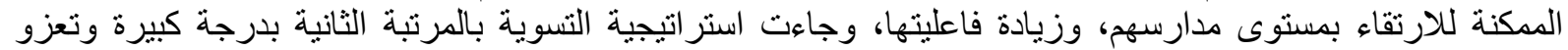

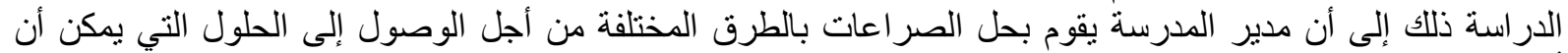

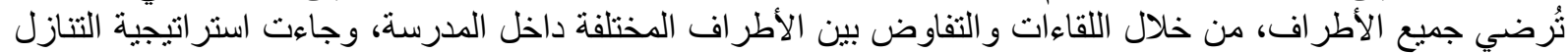

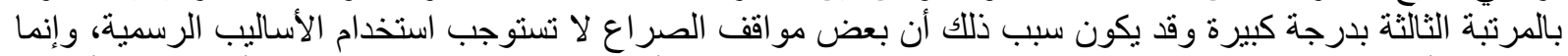

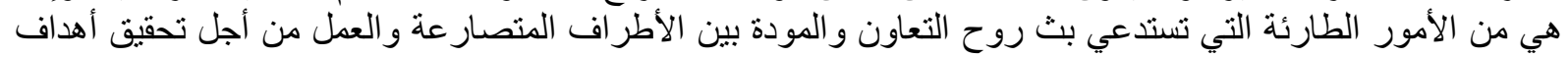

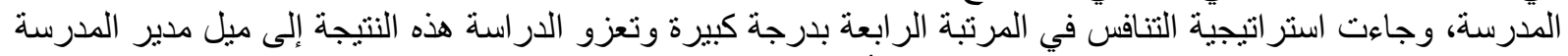

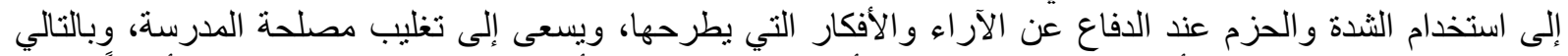

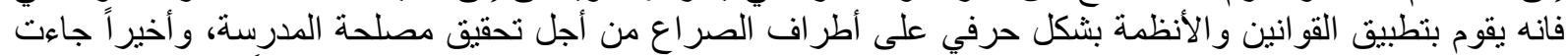

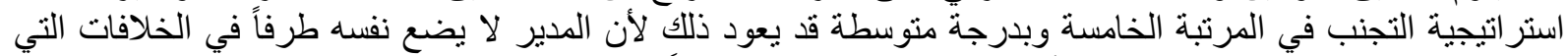

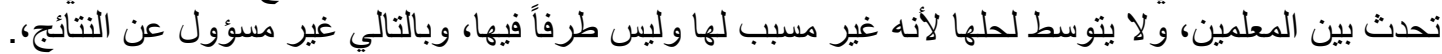

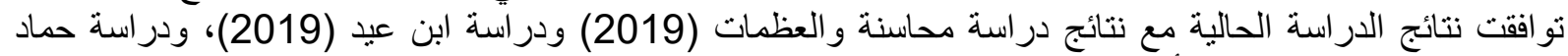

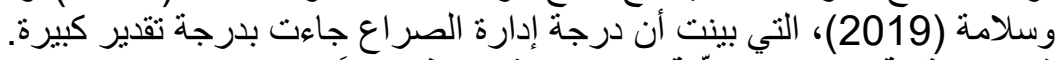

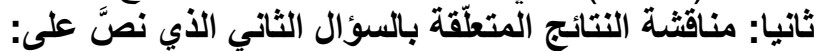

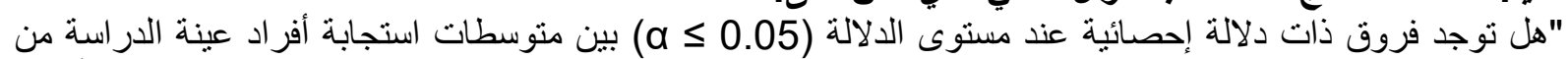

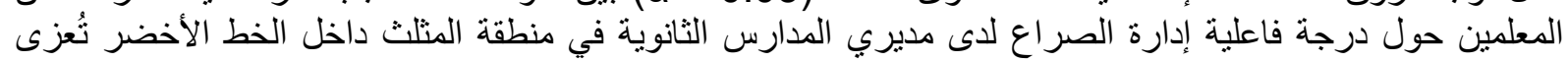

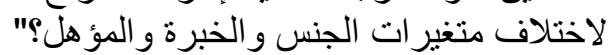

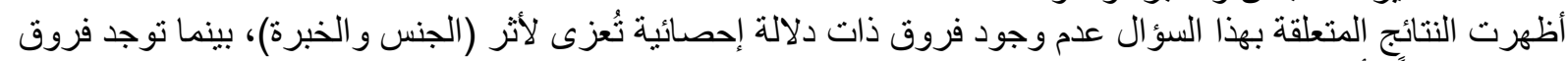

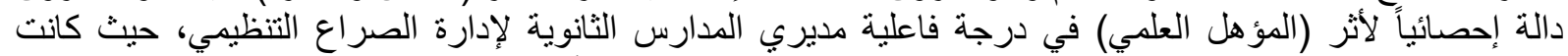

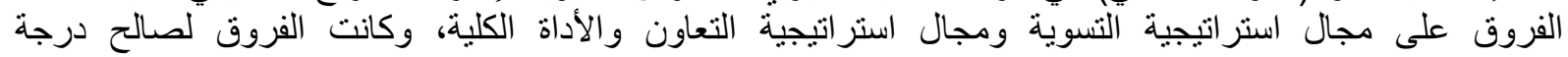

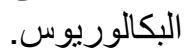

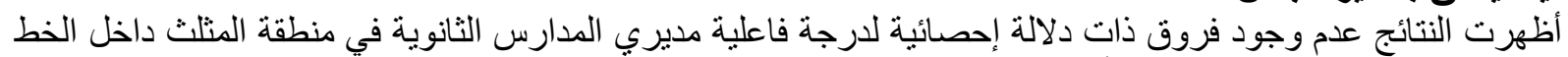

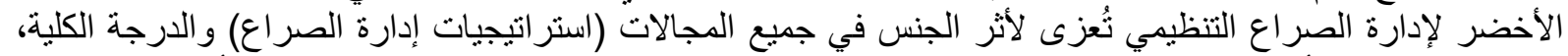

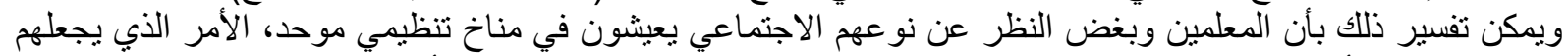

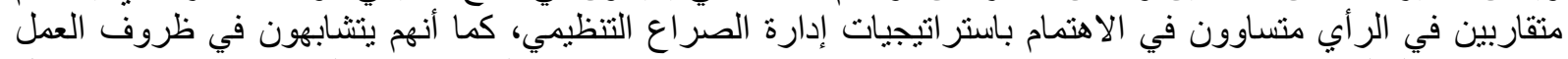

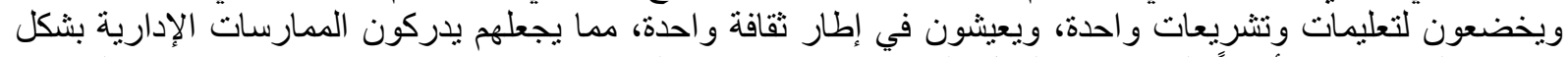

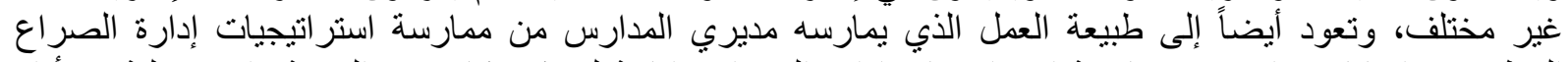

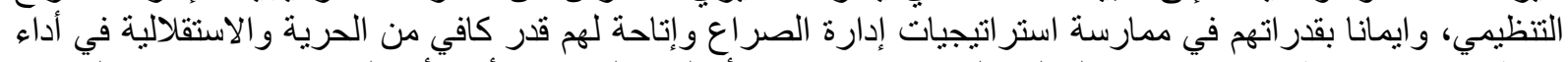

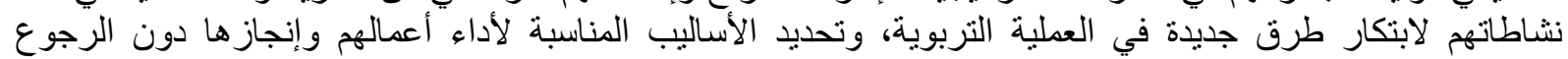

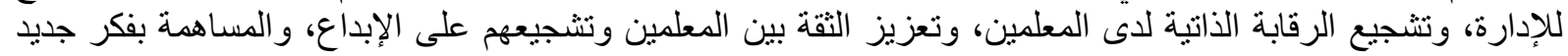

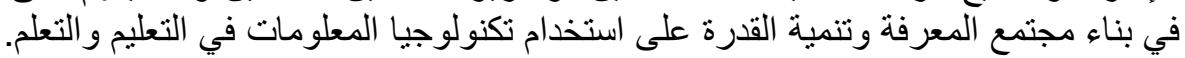

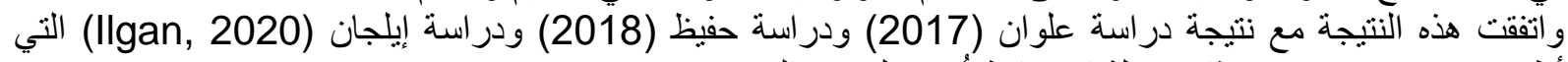

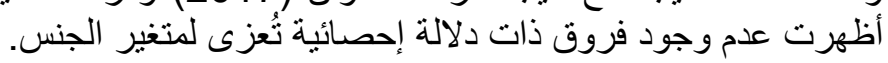

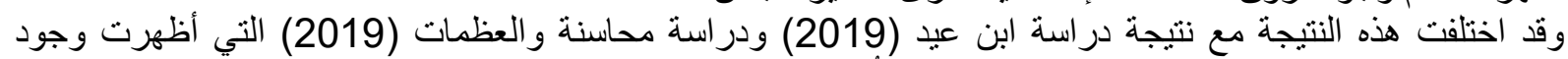

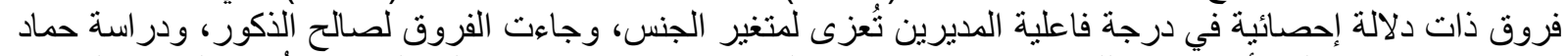

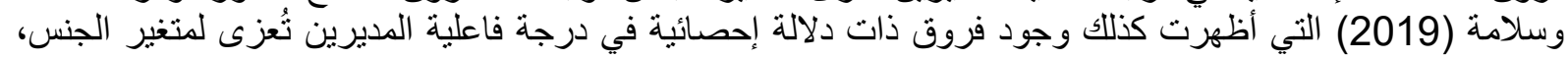
ولكن جاءت الفروق لصنالح الإناث. فيما يتعلق بمتغير الخبرة 


\section{THE DEGREE OF EFFECTIVENESS ORGANIZATIONAL CONFLICT \\ MANAGEMENT BY SECONDARY SCHOOL PRINCIPALS IN THE NORTHERN REGION WITHIN THE GREEN-LINE}

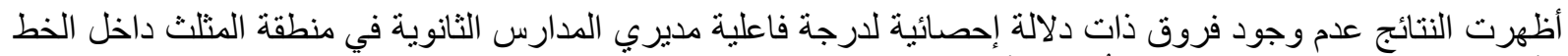

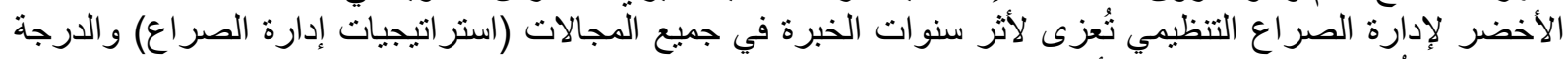

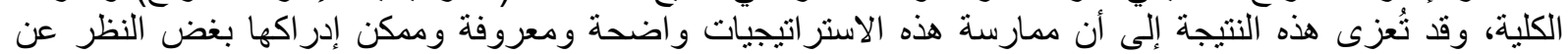

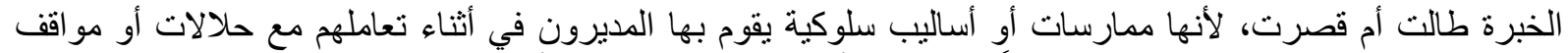

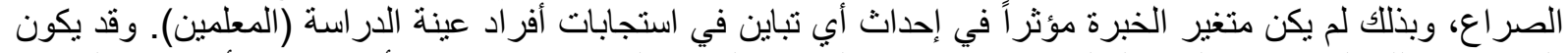

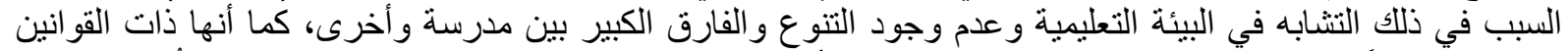

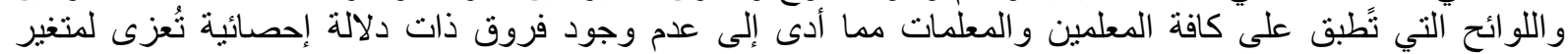
سنوات الخبرة. و اتفقت هذه النتيجة مع نتيجة دراسة علوان (2017) ودر اسة ابن عيد (2019) ودر اسة حماد وسلامة (2019) التي

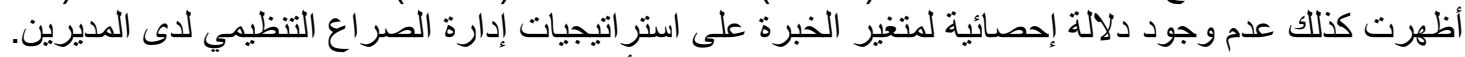

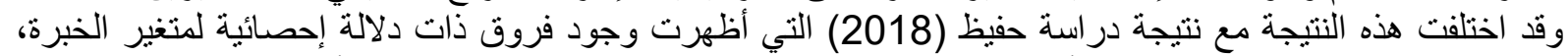

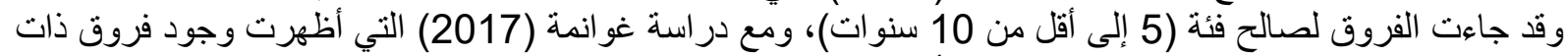

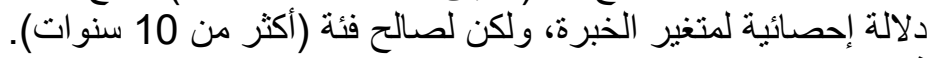
فيما يتعلق بمتغير المؤهل العنير الخبرة

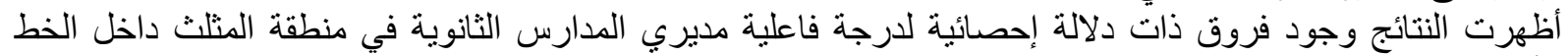

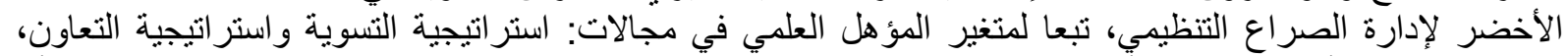

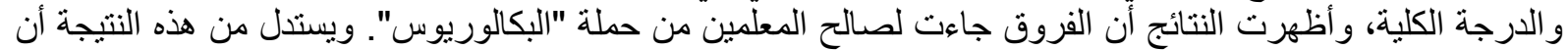

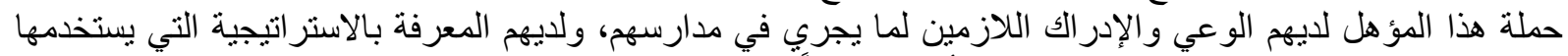

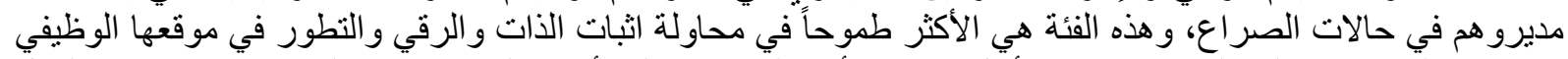

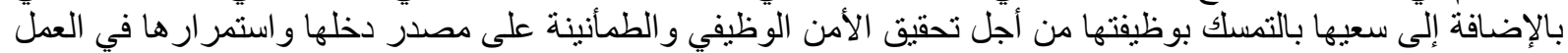

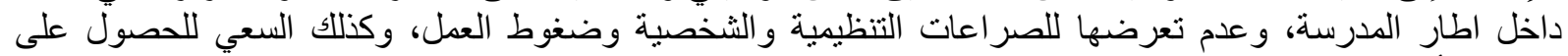

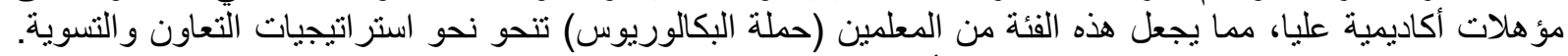

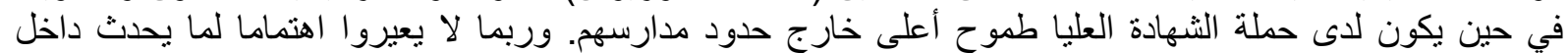

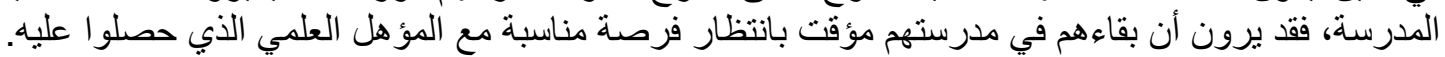

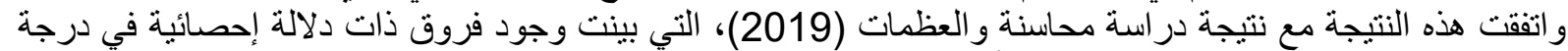

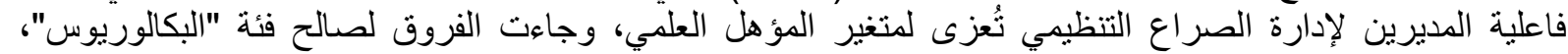

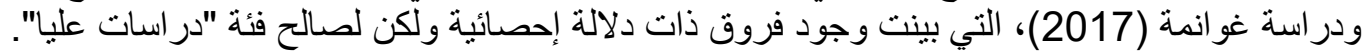

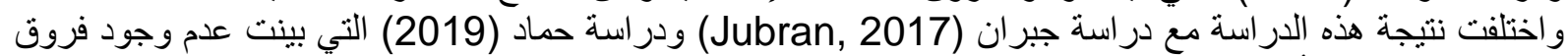
ذات دلالة إحصائية تُعزى لمتغير المؤهل درالجة العلمي.

التوصيات

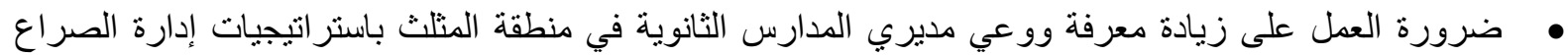

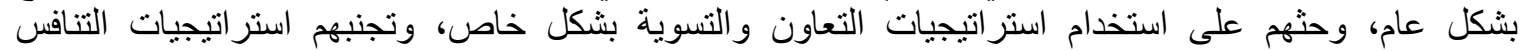

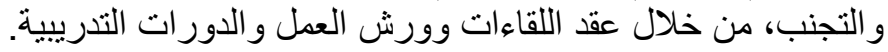

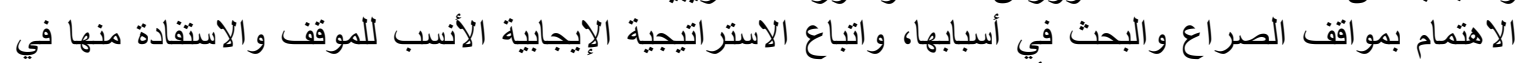
تعزيز العلاقات و الانتماء وتحسين الأداء.

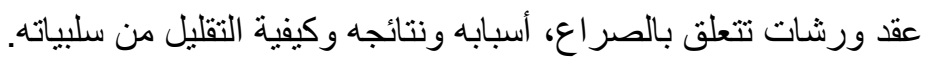
تشجيع المعلمين على حل مشاكلهم دون تدخل مباشر الثر من الإدارة.

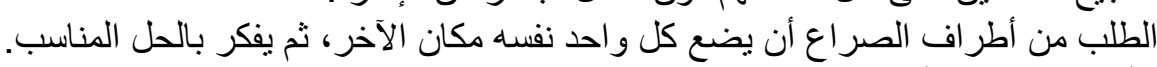
الأخذ بالحسبان الأهداف العليا للمدرسة. تحفيز المديرون للمعلمين بشكل مستمر مما يرفع معنوياتهم ويزيد رضاهم الوظيفي، وزيادة الإنتاجية، ومن ثم الحد من الصر اعات السلبية.

قائمة المراجع 
ابن عيد، يوسف فيصل. (2019). أنماط إدارة الصراع التنظيمي لاى مديري المدارس المتوسطة في دولة الكويت

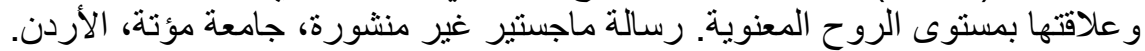

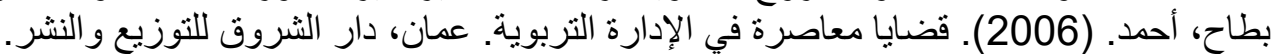

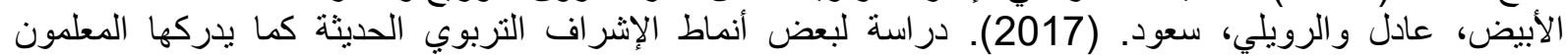

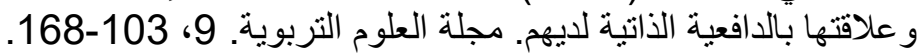

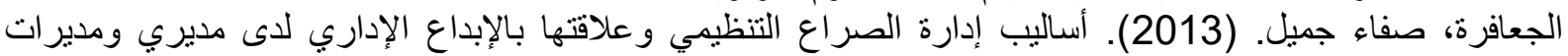
المدارس الحكومية في محافظة الكرك من وجهة نظرهم. دراسئ عاسات العلوم التربوية. 40 (2)، 1663-

حفيظ، ايمان. (2018). استراتيجيات إدارة الصراع التنظيمي لاى مديري المدارس الأساسية الحكومية في العاصمة

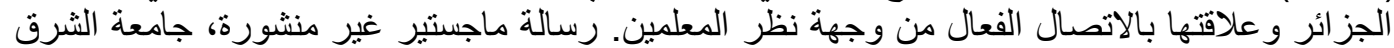
الأوسط، عمان.

حماد، زينب وسلامة، كايد. (2019). درجة فاعلية إدارة الصراع التورئ التظيمي و علاقته بالتمكين الإداري لاى مديري

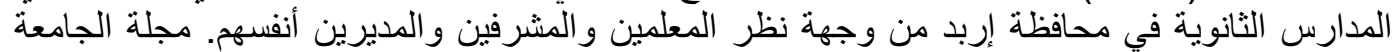

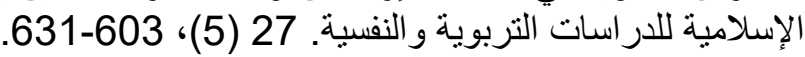

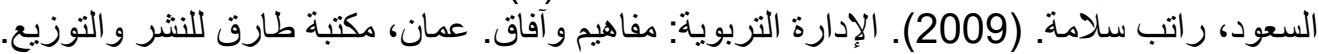

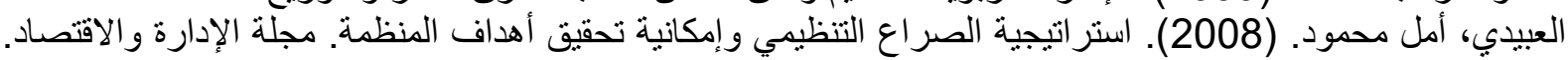
.102-78، 69

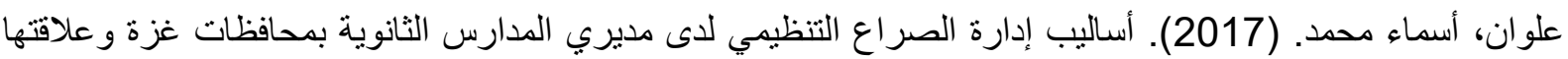

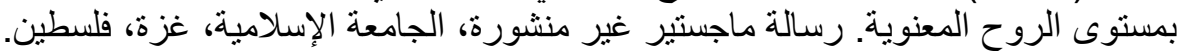

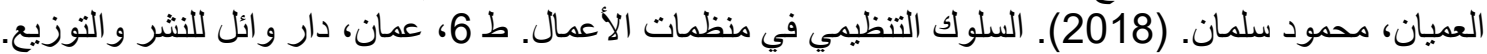

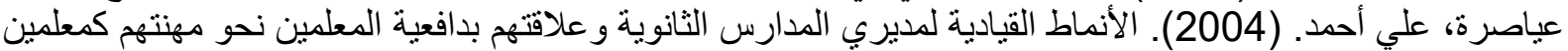
في وزارة التربية والتعليم في الأردن. أطروحة دكتوراه غير منشورة التئ، جامعة عمان العربية للاراسات العليا، عمان.

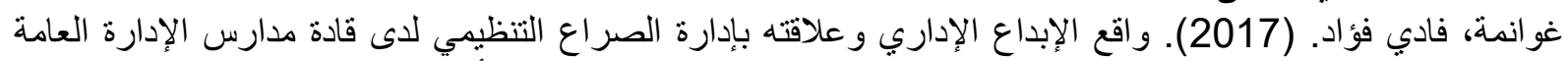

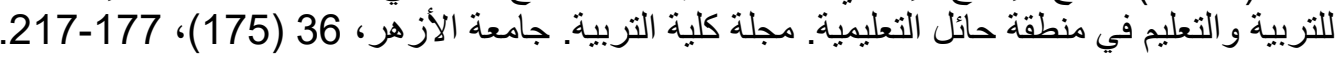

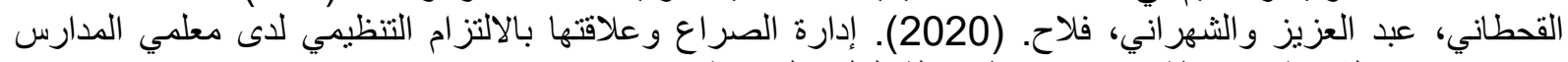

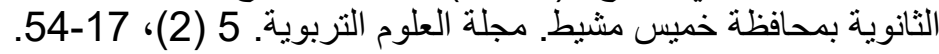

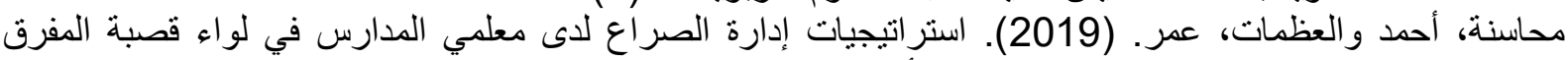

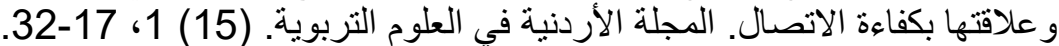

Ferrer, J. B. (2020). Conflict Management Styles of Secondary School Principals and the Relationship of Organizational Climate of the Selected Schools in Quezon City. European Academic Research. 1 (2), 5483-5503.

Ghaffar, A. K. (2019). Conflict in Schools: Its Causes \& Management Strategies. Journal of Managerial and sciences. 3 (2), 212-227.

Ilgan, A. (2020). Examining Principals' Conflict Management Styles: A Study of Turkish Administrators. Bulletin of Education and Research. 42 (2), 1-16.

Jubran, A. M (2017). Organizational Conflict among Teachers and the Principal's Strategies of Dealing with It from the Teachers' Perspective in Schools of Jordan. Journal of Educational and Learning, 6 (1), 54-71.

Radford, J. H. (2013). Assessing Conflict Management Style of Educational Leaders as a Means to Improve Relationships and Effectiveness. (Ph.D. Dissertation) 